\title{
RESEARCH
}

Open Access

\section{Antimutagenic, anti-inflammatory, and antioxidative activities of the juice of Vitis ficifolia var. Ganebu, a woody vine in the grape family, known as Ryukyu-ganebu in Japan}

Sakae Arimoto-Kobayashi ${ }^{1,2^{*}}$ (D, Ryoko Hida ${ }^{2}$, Nana Fujii ${ }^{2}$ and Ryosuke Mochioka ${ }^{3}$

\begin{abstract}
Background: Mutation, inflammation, and oxidative damage including lipid-peroxidation are factors involved in the development of cancer. We investigated the antimutagenic, in vivo and in vitro anti-inflammatory, and antioxidative effects of the juice of Vitis ficifolia var. ganebu (known as Ryukyu-ganebu in Japan) harvested in Kuchinoshima island (hereafter, the juice is referred to as ganebu-K) in comparison with the juice of Vitis coignetiae (crimson glory vine, known as yamabudo in Japan; hereafter, the juice is referred to as yamabudo) which we found antimutagenic and anti-inflammatory effects.
\end{abstract}

Results: Ganebu-K inhibited the mutagenic activity of several carcinogens, MelQx, IQ, Trp-P-2(NHOH), and MNNG, model compounds of tumor initiation. Using S. typhimurium YG7108, a strain lacking $O^{6}$-methylguanine DNA methyltransferases, ganebu-K showed no significant inhibition of the mutagenicity of MNNG. Thus, DNA repair of $\mathrm{O}^{6}$-methylguanine produced by MNNG might be an antimutagenic target of the components in ganebu-K. Topical application of ganebu- $K$ to the dorsal sides of mice resulted in potent suppression of acute edema induced by 12 O-tetradecanoylphorbol-13-acetate (TPA). Ganebu-K, but not yamabudo, exhibited significant inhibition of the induction of prostaglandin $E_{2}$ (PGE2) induced by TPA. Components contained in ganebu-K, but not in yamabudo, might be responsible for the inhibition of the induction of PGE2. Ganebu-K inhibited in vivo lipid peroxidation and decreased the level of glutamic oxaloacetic transaminase induced by $\mathrm{CCL}_{4}$ treatment.

Conclusions: These results suggest that the active components in ganebu-K juice are not the same as those in yamabudo, and the components in ganebu-K are attractive candidates as chemopreventive agents.

Keywords: Antimutagenesis, Anti-inflammation, Acute edema, In vivo anti-lipid peroxidation, Wild grape juice, Ryukyu-ganebu

\footnotetext{
* Correspondence: arimoto@cc.okayama-u.ac.jp

'Graduate School of Medicine, Dentistry and Pharmaceutical Sciences,

Okayama University, 700-8530 Okayama, Japan

${ }^{2}$ Faculty of Pharmaceutical Sciences, Okayama University, 700-8530 Okayama,

Japan

Full list of author information is available at the end of the article
}

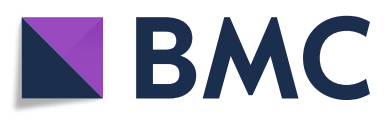

(- The Author(s). 2021 Open Access This article is licensed under a Creative Commons Attribution 4.0 International License, which permits use, sharing, adaptation, distribution and reproduction in any medium or format, as long as you give appropriate credit to the original author(s) and the source, provide a link to the Creative Commons licence, and indicate if changes were made. The images or other third party material in this article are included in the article's Creative Commons licence, unless indicated otherwise in a credit line to the material. If material is not included in the article's Creative Commons licence and your intended use is not permitted by statutory regulation or exceeds the permitted use, you will need to obtain permission directly from the copyright holder. To view a copy of this licence, visit http://creativecommons.org/licenses/by/4.0/. The Creative Commons Public Domain Dedication waiver (http://creativecommons.org/publicdomain/zero/1.0/) applies to the data made available in this article, unless otherwise stated in a credit line to the data. 


\section{Introduction}

Dietary factors can substantially influence cancer risk in humans [1]. Plant metabolites like polyphenols and flavonoids have antioxidant and antiproliferative properties, and can be found in foods such as berries, citrus fruits, tea, and red wine. Fruits and vegetables that contain carotenoids and other antioxidants have been hypothesized to decrease lung cancer risks $[2,3]$. Chemopreventive effects of cyanidin-3-glucoside from blackberry [4], proanthocyanidin extract from grape seed [5], and plant polyphenols [6] on various cancers have been reported. Previously, we found antimutagenic and anti-inflammatory effects of the juice of Vitis coignetiae (crimson glory vine, a deciduous vine that produces purple berries, known as yamabudo in Japan) [7, 8]. We also revealed that the oral intake of a partially purified fraction from yamabudo affords significant protection against skin and lung carcinogenesis in mice. We isolated and identified the non-polyphenolic compound 2,6-dimethoxy-1,4-benzoquinone (DBQ) from yamabudo as an anti-inflammatory substance, and found that it affords significant protection against a tobaccospecific nitrosamine, 4-(methylnitrosamino)-1-(3-pyridyl)1-butanone (NNK), in a mouse model of lung tumorigenesis $[9,10]$. Yamabudo is a wild grape, and seven species and eight varieties of wild grapes including yamabudo are known in Japan [11], but the biological activities of wild grapes other than yamabudo have not been investigated. Vitis ficifolia var. ganebu (known as Ryukyu-ganebu in Japan, and hereafter referred to as Ryukyu-ganebu) is a wild grape that originates in Japan. It is an evergreen vine that produces purple berries that can be processed for juice (hereafter referred to as ganebu). Yamabudo is distributed throughout the mainland (Honshu), Hokkaido, and Shikoku in Japan; Sakhalin island in Russia; and Ulleungdo island in Korea; but not in southern western island in Japan, whereas Ryukyu-ganebu is distributed throughout the southwestern islands of Japan, i.e., Ryukyu and Yaeyama islands in Okinawa Prefecture, and Amami and Tokara islands in Kagoshima Prefecture; but not in mainland, Hokkaido and Shikoku.

Mutation, inflammation, and oxidative damage including lipid-peroxidation are factors involved in the development of cancer [1]. In the present study, we investigated the antimutagenic, anti-inflammatory, and antioxidative effects of ganebu harvested from Kuchinoshima island in comparison with yamabudo.

\section{Materials and methods Materials}

V. ficifolia var. ganebu (Ryukyu-ganebu in Japanese) grows naturally in Kuchinoshima island in Kagoshima Prefecture, Japan. Kuchinoshima island of the Tokara islands is the northern limit of the natural habitat of ganebu. Fruits of ganebu grown in Kuchinoshima were harvested in 2011 and processed with a juicer. Juice $(660 \mathrm{~mL})$ was obtained from $1 \mathrm{~kg}$ of fruits. The juice was centrifuged with $3500 \mathrm{rpm}$ (2000 x g) for $15 \mathrm{~min}$ at $20{ }^{\circ} \mathrm{C}$, and supernatant was obtained (hereafter, the obtained supernatant is referred to as ganebu-K). As the dry weight of $1 \mathrm{~mL}$ of ganebu-K was $0.461 \mathrm{~g}$, the concentration of ganebu-K was $461 \mathrm{mg} / \mathrm{mL}$. Juice of the fruits of $V$. coignetiae cultivated in Hiruzen (Okayama, Japan) and harvested in 2013 was purchased in local stores in Okayama. The juice was centrifuged with $3500 \mathrm{rpm}$ (2000 x g) for $15 \mathrm{~min}$ at $20{ }^{\circ} \mathrm{C}$, and supernatant was obtained (hereafter, the obtained supernatant is referred to as yamabudo). As the dry weight of $1 \mathrm{~mL}$ of yamabudo was $0.188 \mathrm{~g}$, the concentration of yamabudo was $188 \mathrm{mg} /$ $\mathrm{mL}$. Samples were sterilized by filtration and kept at $-20{ }^{\circ} \mathrm{C}$ until use.

Salmonella enterica subspecies I, serovar Typhimurium (Salmonella typhimurium) strain TA98 [hisD3052 $\triangle u v r B$ gal bio chl1005 rfa1001/pKM101], TA100 [hisG46 $\Delta u v r B$ gal bio chl1005 rfa1001/pKM101], and TA1535 [hisG46 $\Delta u v r B$ gal bio chl1005 rfa1001] were gifts from Dr. Bruce N. Ames of the University of California, Berkeley [12]. S. typhimurium YG7108 [hisG46 $\Delta u v r B$ gal bio chl1005 rfa1001 $\left.\Delta a d a_{s t}:: \mathrm{Km}^{r} \Delta \operatorname{ogt}_{s t}:: \mathrm{Cm}^{r}\right]$, a strain lacking $O^{6}$-methylguanine DNA methyltransferases, was a gift from Dr. Masami Yamada of the National Institute of Health Sciences [13]. 2-Amino-3,8dimethyl-3 $H$-imidazo[4,5-f]quinoxaline (MeIQx, CAS 77500-04-0), 2-amino-3-methylimidazo(4,5-f)quinoline (IQ, CAS 76180-96-6), 3-amino-1-methyl-5 H-pyrido[4,3-b]indole (Trp-P-2, CAS 72254-58-1), carbon tetrachloride and 7,12-dimethylbenz(a)anthracene (DMBA, CAS 57-97-6), 2,6-dimethoxy-1,4-benzoquinone (DBQ) (CAS 530-55-2), and 12-O-tetradecanoylphorbol-13-acetate (TPA) were purchased from FUJIFILM Wako Pure Chemical Corporation (Osaka, Japan). 1-Methyl-3-nitro-1-nitrosoguanidine (MNNG, CAS 70-25-7) was purchased from Nacalai Tesque (Kyoto, Japan). tert-Butyl hydroperoxide (t-BHP) was purchased from Sigma-Aldrich Japan (Tokyo). A metabolically activated form of Trp-P-2, 3-hydroxyamino-1methyl-5 $H$-pyrido[4,3- $b$ ] indole (Trp-P-2(NHOH)), was synthesized from Trp-P-2 according to steps outlined in the literature [14]. The supernatant fraction of rat liver homogenate (S9) was prepared from male Sprague-Dawley rats that had been administered polychlorinated biphenyl (PCB54, with a chlorine content of $54 \%$, Tokyo Kasei, Tokyo). The protein content of the S9 fraction was $43.0 \mathrm{mg} / \mathrm{mL}$. Other reagents were purchased from commercial sources. All experiments were carried out in accordance with the Safety Guidelines of Okayama University, and Industrial Safety and Health Act No. 71 of 2018. 


\section{Animals}

Mice (ICR Slc male) and Sprague-Dawley rats were purchased from Japan SLC, Inc. (Hamamatsu, Japan). SENC $\mathrm{AR}$ mice were born and reared in our laboratory. Animals were housed five per cage in the animal room and randomly separated to form treatment groups at least one week prior to commencement of the experiment. Mice had free access to pellets of murine chow (MF powder, Oriental Yeast Co. Ltd., Tokyo, Japan) and water, and were kept on a 12-h light/12-h dark cycle with optimum air changes and a constant room temperature of $20{ }^{\circ} \mathrm{C}$. All experiments were performed in accordance with the Guidelines for Animal Experiments at Okayama University Advanced Science Research Center (Permission No. OKU-2,012,213, $2,015,045,2,018,028,2,018,787$, and 2,021,460) based on the Act on Welfare and Management of Animals (Act of Japan, No. 105 of October 1, 1973 and Amendment of Act No. 68 of 2005) and standards relating to the Care and Keeping and Reducing Pain of Laboratory Animals (Notice of the Ministry of the Environment No. 88 of 2006).

\section{Antimutagenicity test}

The inhibitory effects of juice on the mutagenicity induced by MeIQx, IQ, Trp-P-2(NHOH), DMBA, and MNNG were investigated using the Ames test [12] as previously described [15]. MeIQx and IQ were assayed with S. typhimurium TA98 in the presence of metabolic activation with rat liver homogenate $S 9$ (hereafter referred to as $+\mathrm{S} 9)$. Trp-P-2(NHOH) was assayed with S. typhimurium TA98 in the absence of metabolic activation (hereafter referred to as -S9). DMBA was assayed with S. typhimurium TA100 with +S9. MNNG was assayed with S. typhimurium TA1535 and YG7108 with -S9. Experiments were performed in triplicate. The mutagenic activities (\%) as shown in Fig. 1 were calculated as follows:

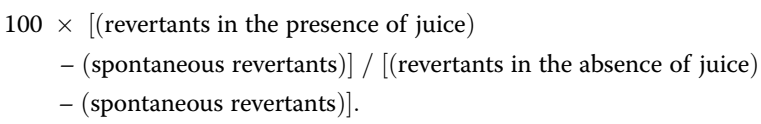

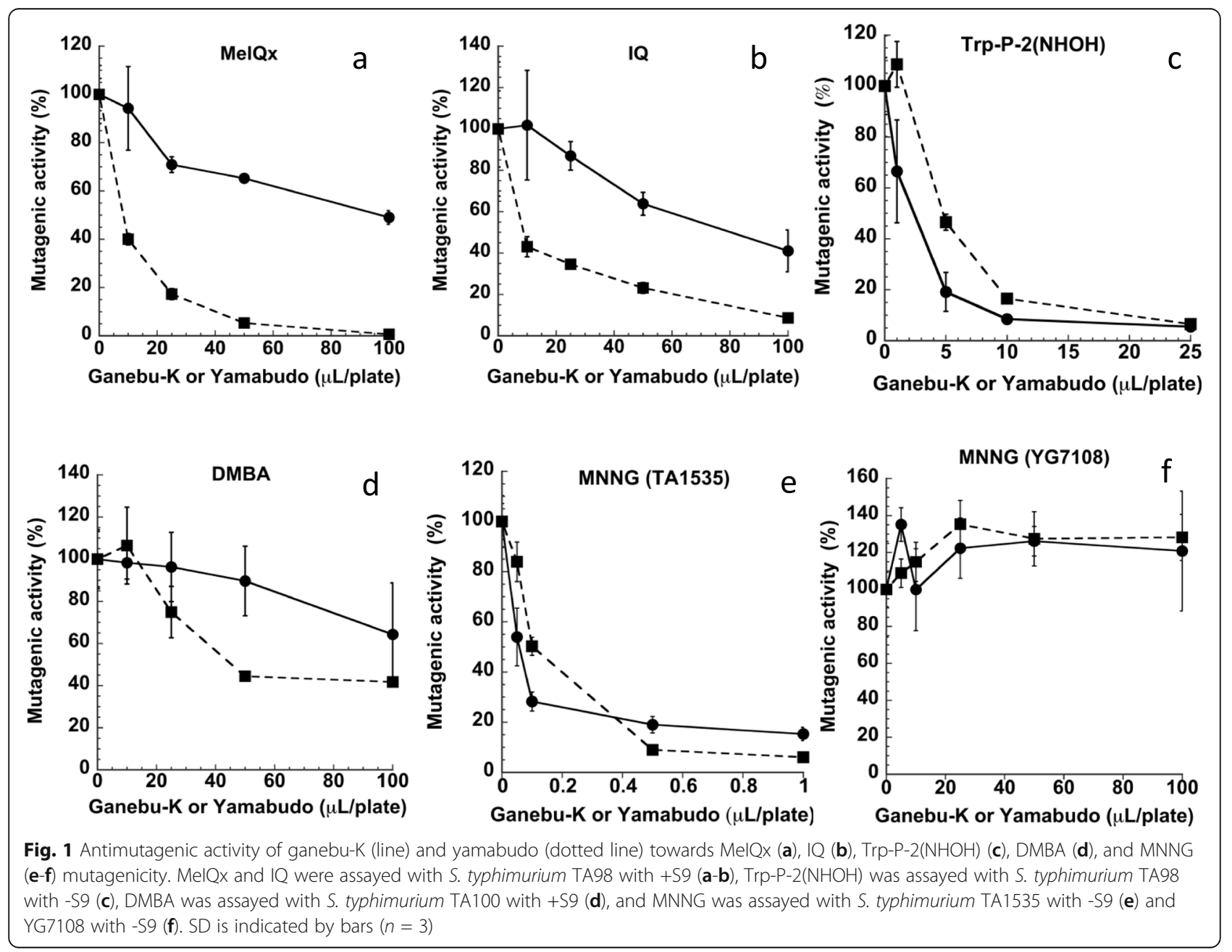




\section{Effects on TPA-induced acute edema on the dorsal sides of mice}

Juice (ganebu-K or yamabudo) was mixed with an equal volume of acetone for better permeability into skin. Sixweek-old male SENCAR mice were divided into five groups each comprising five animals. The dorsal side of the skin of mice was shaved using an electric hair cutter at least one day before treatments. Samples were topically applied on a circle $(2 \mathrm{~cm}$ in diameter $)$ on the dorsal sides of mice. Mice in groups 1-2 received $20 \mu \mathrm{L}$ of acetone:water (1:1), mice in group 3 received $20 \mu \mathrm{L}$ of yamabudo, mice in group 4 received $20 \mu \mathrm{L}$ of DBQ ( $1 \mathrm{mg} /$ $\mathrm{mL}$ ) dissolved in acetone:water (1:1), and mice in group 5 received $20 \mu \mathrm{L}$ of ganebu-K. After $30 \mathrm{~min}$, mice in group 1 received acetone without TPA applied on the circle, while mice in groups 2-5 each received 1.7 nmole of TPA dissolved in $20 \mu \mathrm{L}$ of acetone applied on the circle. Thirty minutes following acetone/TPA treatment, the thickness of dorsal skin was measured with a Digital Caliper (AS ONE Corporation, Osaka, Japan). Edema was quantified as the difference of the thickness between treatments. Inhibition rate (\%) of inflammation was calculated as follows:

$$
\begin{aligned}
& 100 \times\{1-\text { average skin thickness of groups } 3,4, \text { or } 5) \\
& \quad-(\text { average skin thickness of group } 1)] /[(\text { average skin thickness of group } 2) \\
& -(\text { average skin thickness of group } 1)]\}
\end{aligned}
$$

The results of mice in group 1 represented a negative control (NC), those of group 2 indicated the effects with TPA as a positive control (PC), and those of groups 3-5 represented the effects of TPA in the presence of yamabudo (group 3), DBQ (group 4), or ganebu-K (group 5) as shown in Fig. 2a.

Prostaglandin E2 (PGE2) induction in treated skin was measured as follows. Briefly, mice were sacrificed, and circular Sect. (6 $\mathrm{mm}$ in diameter) in the treated circles ( $2 \mathrm{~cm}$ in diameter as described above) of treated dorsal skin were punched out using a cork borer and frozen with liquid $\mathrm{N}_{2}$ until use. Obtained skin was homogenized in cold $0.1 \mathrm{M}$ sodium phosphate buffer ( $\mathrm{pH} 7.4$ ) containing $1 \mathrm{mM}$ EDTA and $10 \mu \mathrm{g} / \mathrm{mL}$ indomethacin. Homogenates were centrifuged at $10,000 \times \mathrm{g}$ for $30 \mathrm{~min}$ at $4{ }^{\circ} \mathrm{C}$, and the supernatant fraction was used for the analysis of PGE2 induction. PGE2 was measured using a commercial assay kit (Prostaglandin E2 Parameter Assay Kit, R\&D Systems, MN, USA) according to the manufacturer's instructions. Results are shown in Fig. 2b. The inhibition rates of PGE2 levels (\%) were calculated similar to those formerly described.

\section{In vitro preventive effects of oxidative damage, including lipid peroxidation}

Thiobarbituric acid reactive substance (TBARS) assays were used for the in vitro anti-lipid peroxidation study of ganebu-K. Ganebu-K was freeze-dried and dissolved and diluted in water to obtain various concentrations, $0.5 \%, 1 \%, 5 \%$, and $10 \%$ eq. of the original juice. Livers from non-treated mice (SENCAR, male, seven weeks old, $n=3$ ) were homogenized with phosphate buffer $(\mathrm{pH} 7.0,50 \mathrm{mM})$ and centrifuged $\left(15 \mathrm{~min}, 9000 \mathrm{~g}, 4{ }^{\circ} \mathrm{C}\right)$. The obtained liver supernatant $(50 \mu \mathrm{L}), \mathrm{t}-\mathrm{BHP}(1 \mathrm{M}, 2$ $\mu \mathrm{L})$, and $48 \mu \mathrm{L}$ of various concentrations of ganebu-K $(0$, $0.5,1,5$, or $10 \%$ in water, as indicated in Fig. 3) were

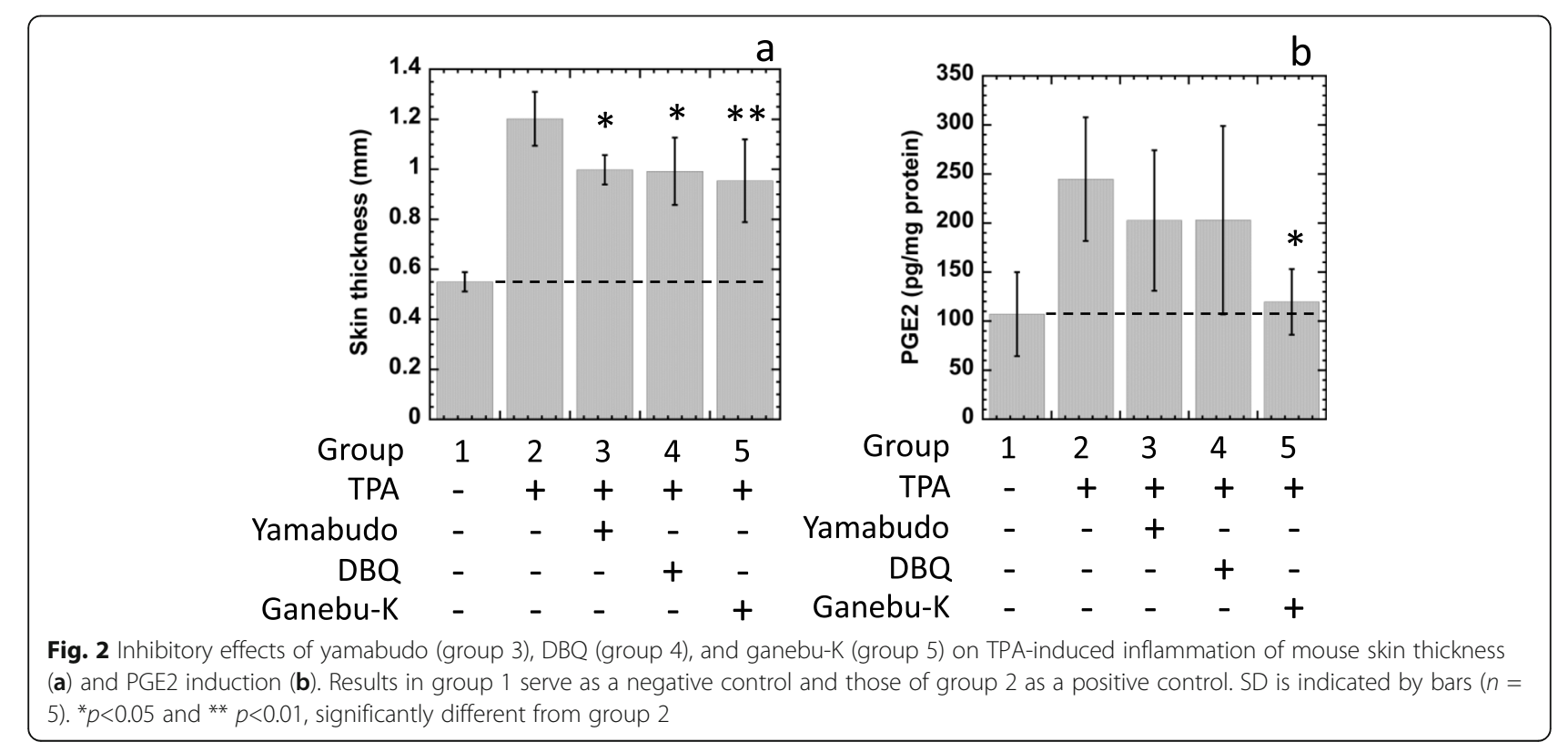


mixed and incubated at $37{ }^{\circ} \mathrm{C}$ for $2 \mathrm{~h}$. For the $\mathrm{NC}$, the liver supernatant $(50 \mu \mathrm{L})$ and solvent $(50 \mu \mathrm{L})$ were mixed without t-BHP and incubated as above. The amounts of malondialdehyde produced were determined by the TBARS method using a TBARS assay kit (Cayman, Ann Arbor, MI, USA).

\section{Protective effects on carbon tetrachloride-induced hepatic dysfunction}

We evaluated the hepatoprotective effects against carbon tetrachloride-induced in vivo hepatotoxicity. Briefly, mice (ICR, six weeks old, male) were divided into five groups of five animals (groups I-V). Mice in groups I and II received $10 \mathrm{~mL} / \mathrm{kg}$ of water, mice in group III received $10 \mathrm{~mL} / \mathrm{kg}$ of yamabudo, mice in group IV received $10 \mathrm{~mL} / \mathrm{kg}$ of DBQ (1 mg/mL dissolved in water), and mice in group $\mathrm{V}$ received $10 \mathrm{~mL} / \mathrm{kg}$ of ganebu-K via gavage once a day for three days. Thirty minutes after the third gavage, mice were injected with $1 \mathrm{~mL} / \mathrm{kg}$ of corn oil (for group I) or $1 \mathrm{~mL} / \mathrm{kg}$ of $50 \%$ carbon tetrachloride dissolved in corn oil (for groups II-V) with a single ip injection. Twenty-four hours after injection, mice were sacrificed, venous blood was obtained via the abdominal aorta, and livers were collected. TBARS assays were used to measure in vivo anti-lipid peroxidation in carbon tetrachloride-treated livers. Briefly, obtained livers were homogenized with sodium phosphate buffer $(\mathrm{pH} 7.0,50 \mathrm{mM})$ and centrifuged (15 min, 10,000 x g, $\left.4{ }^{\circ} \mathrm{C}\right)$. Supernatants were collected, and the levels of 2 thiobarbituric acid reactive substances (TBARS) were determined with a TBARS assay kit (Cayman, MI, USA)

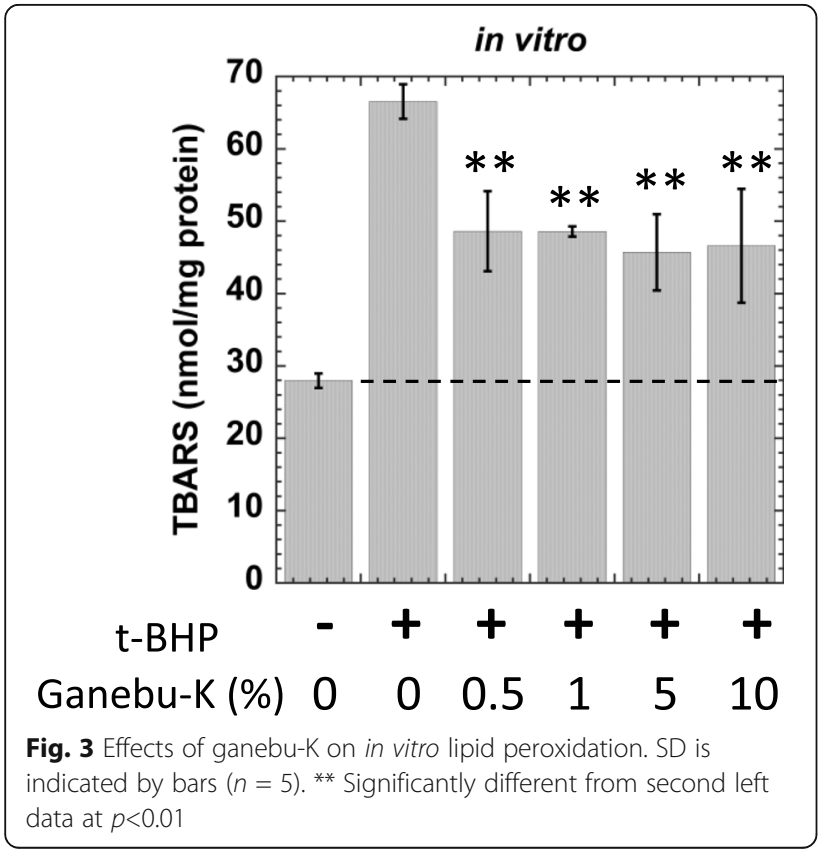

(Fig. 4a). Blood was centrifuged with heparin, and plasma was taken to determine glutamic oxaloacetic transaminase (GOT) levels (Fig. 4b). GOT was measured using an assay kit (Transaminase CII test) purchased from FUJIFILM Wako Pure Chemical Corporation. The inhibition rate of TBARS and GOT levels (\%) were calculated similar to those formerly described.

\section{Statistical analyses}

Data are expressed as means \pm standard deviation for each data point as indicated in each figure. $P$ values < 0.05 were considered to be statistically significant. Statistical analyses were performed using KaleidaGraph (Synergy Software, Reading, PA) and Excel add-in software, Excel statistics (SSRI Co. Ltd., Tokyo, Japan).

\section{Results}

Antimutagenesis study with ganebu-K and yamabudo

The mutagenicity of MeIQx and IQ detected using TA98 in the presence of S9 was inhibited in the presence of ganebu-K in a dose-dependent manner, and yamabudo also inhibited the mutagenicity of MeIQx and IQ (Fig. 1ab). The amounts (volume) of ganebu-K needed for $50 \%$ inhibition (hereafter referred as to $\left.\mathrm{ID}_{50(\mathrm{~V})}\right)$ of the mutagenicity of MeIQx and IQ were approximately $100 \mu \mathrm{L} /$ plate (Fig. 1a) and $80 \mu \mathrm{L} /$ plate (Fig. 1b), respectively. As the concentration of ganebu-K was $461 \mathrm{mg} / \mathrm{mL}$, the amounts (weight) of ganebu-K needed for $50 \%$ inhibition (hereafter referred as to $\left.\mathrm{ID}_{50(\mathrm{~W})}\right)$ of the mutagenicity of MeIQx and IQ were approximately $46.1 \mathrm{mg} /$ plate and $36.9 \mathrm{mg} /$ plate, respectively. The $\mathrm{ID}_{50(\mathrm{~V})}$ and $\mathrm{ID}_{50(\mathrm{~W})}$ values for yamabudo were each approximately $10 \mu \mathrm{L} /$ plate and $1.88 \mathrm{mg} /$ plate for the mutagenicity of MeIQx and IQ (Fig. 1ab), as the concentration of yamabudo was $188 \mathrm{mg} / \mathrm{mL}$. The mutagenicity of Trp-P-2(NHOH) detected with TA98 (-S9) was also inhibited in the presence of ganebu-K or yamabudo (Fig. 1c). The $\mathrm{ID}_{50(\mathrm{~V})}$ and $\mathrm{ID}_{50(\mathrm{~W})}$ for ganebu-K was approximately $2 \mu \mathrm{L} /$ plate and $0.922 \mathrm{mg} /$ plate, and those for yamabudo was approximately $5 \mu \mathrm{L} /$ plate and $0.94 \mathrm{mg} /$ plate (Fig. 1c). The mutagenicity of DMBA detected using TA100 with + S9 was inhibited in the presence of yamabudo, but not significantly inhibited in the presence of ganebu-K (Fig. 1d). The ID $_{50}$ for yamabudo was approximately $40 \mu \mathrm{L} /$ plate and $7.52 \mathrm{mg} /$ plate against the mutagenicity of DMBA (Fig. 1d). The mutagenicity of MNNG detected with TA1535 (-S9) was inhibited in the presence of ganebu- $K$ and yamabudo in a dosedependent manner, respectively (Fig. 1e). The $\mathrm{ID}_{50}$ against the mutagenicity of MNNG detected with TA1535 (-S9) was approximately $0.050 \mu \mathrm{L} /$ plate and $23.1 \mu \mathrm{g} /$ plate for ganebu-K, and $0.1 \mu \mathrm{L} /$ plate and $18.8 \mu \mathrm{g} /$ plate for yamabudo. However, the mutagenicity 


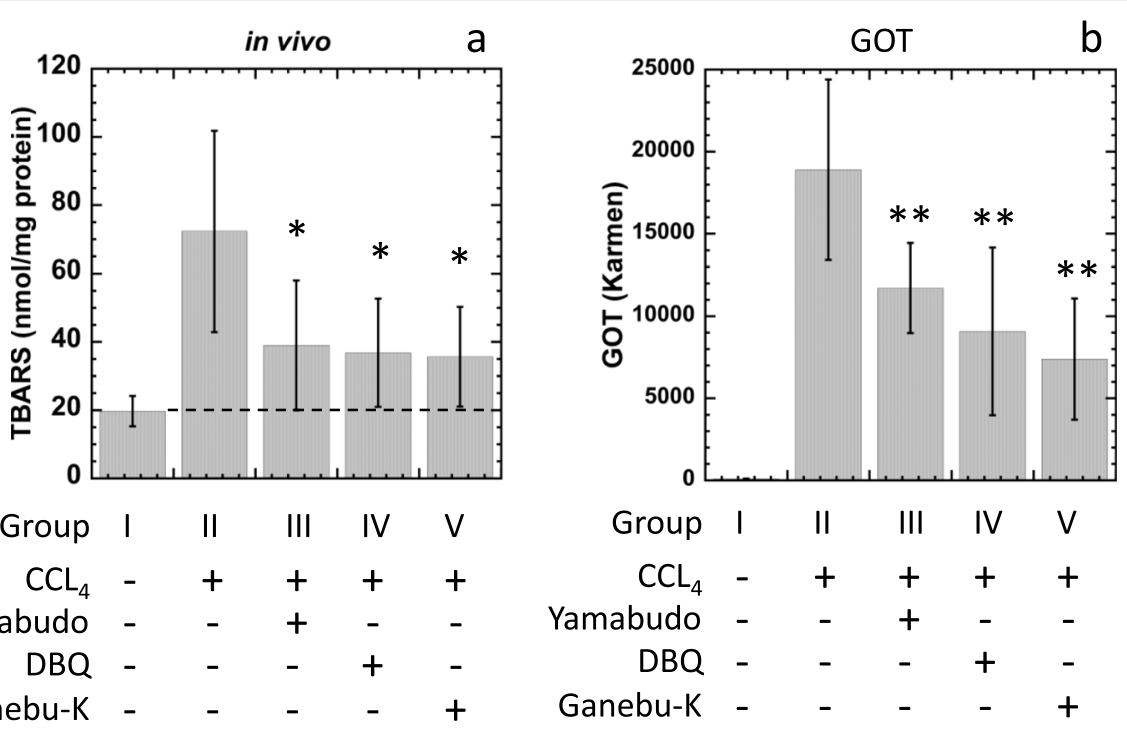

Fig. 4 Effects of yamabudo (group 3), DBQ (group 4), and ganebu-K (group 5) on in vivo lipid peroxidation (a) and on plasma GOT levels (b). Results in group 1 serve as a negative control and those of group 2 as a positive control. SD is indicated by bars $(n=5)$. ${ }^{*} p<0.05$ and ${ }^{* *} p<0.01$, significantly different from group II

of MNNG detected using YG7108 with -S9 was not inhibited in the presence of ganebu-K or yamabudo up to $100 \mu \mathrm{L} /$ plate (Fig. 1f).

The number of $\mathrm{His}^{+}$revertants per plate in the absence of ganebu nor yamabudo ( $100 \%$ values of mutagenicity) was $1242 \pm 82$ for 200 pmole of MeIQx (TA98, + S9), $1394 \pm 442$ for 80 pmole of IQ (TA98, +S9), 2700 \pm 301 for 20 pmole of Trp-P-2(NHOH) (TA98, -S9), $1697 \pm 213$ for 50 nmole of DMBA (TA100, + S9), 3713 \pm 321 for 4 nmole of MNNG (TA1535, -S9), and $1043 \pm$ 193 for 0.1 nmole of MNNG (YG7108, -S9). The number of spontaneous $\mathrm{His}^{+}$revertants per plate (negative control) found in the absence of ganebu, yamabudo, and mutagens was $21.3 \pm 12.1$ for TA98 $(+S 9), 33.9 \pm 11.3$ for TA98 (-S9), $135.3 \pm 41.2$ for TA100 (+S9), $8.6 \pm 3.4$ for TA1535 (-S9), and $12.0 \pm 3.6$ for YG7108 (-S9).

\section{Effects on TPA-induced acute edema on dorsal side of mouse}

Since ganebu-K inhibited the mutagenicity of the carcinogens above mentioned (Fig. 1), we further investigated its biological activities. The anti-inflammatory activity of ganebu-K as well as yamabudo and DBQ were evaluated in a mouse model (Fig. 2). The skin thicknesses of mice treated with TPA (group 2) were significantly increased compared with mock-treated skin of mice in group 1 (Fig. 2a), so a single topical application of TPA induced dorsal edema in mice. TPA-induced edema of mice on the dorsal side was significantly inhibited with topical application of yamabudo (group 3), DBQ (group 4), and ganebu-K (group 5) from group 2, respectively. Average rates of the inhibition of the inflammation were $31.3 \pm$
$9.0 \%$ (group 3), $32.2 \pm 20.6 \%$ (group 4), and $38.0 \pm$ $25.4 \%$ (group 5), respectively (Fig. 2a). Statistical analysis was performed with Dunnett test following one-way ANOVA (Fig. 2ab). Two-sided test was performed.

The amounts of PGE2 in TPA-treated skin of mice in group 2 were significantly increased compared with mock-treated skin of mice in group 1 (Fig. 2b). Topically applied ganebu-K, but not yamabudo or $\mathrm{DBQ}$, significantly inhibited the PGE2 induction of TPA treatment compared with group 2. The inhibition rate of PGE2 induction (\%) in the presence of ganebu-K was calculated as $91.0 \% \pm 24.3 \%$ (Fig. 2 b).

\section{In vitro lipid peroxidation study}

We investigated the preventive effects of ganebu-K on oxidative damage, including lipid peroxidation. TBARS levels in liver supernatants were increased by treatment with $t$-BHP. In the presence of ganebu-K (from 0.5 to $10 \%$ eq. of the original juice), TBARS levels in the supernatants of $t$-BHP-treated livers significantly decreased by $50 \%$ (Fig. 3). No dose-responsible effects of ganebu-K on TBARS levels was observed. Statistical analysis was performed with Dunnett test following one-way ANOVA and significant difference from positive control (+ $t$-BHP \& $0 \%$ ganebu-K) was analyzed.

\section{In vivo protective effects against carbon tetrachloride- induced hepatic dysfunction}

We investigated the preventive effects on in vivo oxidative damage, including lipid peroxidation, caused by $\mathrm{CCL}_{4}$ toxicity. TBARS levels in the liver were increased with $\mathrm{CCL}_{4}$ injection (group II) compared with the 
mock-injected group (group I) (Fig. 4a). TBARS levels in the livers of mice injected with $\mathrm{CCL}_{4}$ and orally administered yamabudo (group III), DBQ (group IV), or ganebu$\mathrm{K}$ (group V) were significantly decreased compared with group II (Fig. 4a). The inhibition rates (\%) of TBARS levels after oral administration of yamabudo, DBQ, or ganebu-K were calculated as $63.3 \%, 67.5 \%$, and $69.8 \%$, respectively. GOT levels in blood plasma were also increased with $\mathrm{CCL}_{4}$ injection (group II) compared with the mock-injected group (group I) (Fig. 4b). GOT levels of mice injected with $\mathrm{CCL}_{4}$ and orally given yamabudo (group III), DBQ (group IV), or ganebu-K (group V) were significantly decreased compared with group II (Fig. 4b). The inhibition rates (\%) of GOT levels with oral administration of yamabudo, $\mathrm{DBQ}$, or ganebu-K were calculated as $38.2 \%, 40.5 \%$, and $61.2 \%$, respectively. Statistical analysis was performed with Dunnett test following one-way ANOVA and significant difference from group 2 was analyzed.

\section{Discussion}

We investigated the biological activities of ganebu-K in comparison with yamabudo. As a working hypothesis, we supposed that ganebu- $\mathrm{K}$ has antimutagenic, antiinflammatory, and antioxidative activities similar to yamabudo. We investigated the antimutagenic effects of ganebu juice on well-known mutagenic carcinogens such as heterocyclic amines (MeIQx, and IQ), an activated heterocyclic amine (Trp-P-2(NHOH)), a polyaromatic hydrocarbon (DMBA), and an alkylating agent (MNNG) using the Ames test. The results showed that ganebu-K juice inhibited the mutagenicity of MeIQx and IQ, but not $\mathrm{DMBQ}$, in the presence of metabolic activation. MeIQx, IQ, and DMBQ require metabolic activation to be mutagenic $[16,17]$. Previously, we found that yamabudo decreased the activities of phase I enzymes (EROD and MROD) and increased the activities of phase II bioinactivation enzymes (UGT and GST) [7]. MeIQx and IQ undergo N-hydroxylation by P450 1A2 as a first step of metabolic activation, and DMBA is metabolized to oxidized forms, for example epoxide and diol derivatives, by P450 1B1 [18]. Modulation of metabolic enzymes could be one antimutagenic mechanism against the genotoxicity of MeIQx, IQ, and DMBQ. The $\mathrm{ID}_{50}(\mathrm{~W})$ values of ganebu-K against the mutagenicity of MeIQx and IQ were approximately twenty-five and twenty times higher than those of yamabudo, indicating that the concentration of antimutagenic components in ganebu- $\mathrm{K}$ might be one-25th or one-twentieth that of yamabudo (Fig. 1ab). The concentration of antimutagenic components in ganebu-K might be insufficient for antimutagenicity towards DMBA (Fig. 1d). Ganebu-K juice also inhibited the mutagenicity of an $\mathrm{N}$-hydroxylated heterocyclic amine, Trp-P-2(NHOH), in the absence of metabolic activation (Fig. 1c). Degradation of Trp-P$2(\mathrm{NHOH})$ is stimulated in the presence of purpurin [19] and superoxide dismutase [20]. The components in ganebu-K, as well as yamabudo, might accelerate the degradation of Trp-P-2(NHOH) to reduce the mutagenicity of Trp-P-2(NHOH). The $\mathrm{ID}_{50}$ of ganebu-K for Trp-P-2(NHOH), $0.922 \mathrm{mg} /$ plate, was much smaller than those for MeIQx and IQ, at $46.1 \mathrm{mg} /$ plate. Lower amounts of components in ganebu-K might be sufficient for the degradation of Trp-P-2(NHOH) compared with the suppression of $\mathrm{S} 9$ enzymes required for the mutagenicity of MeIQx and IQ.

We investigated whether ganebu can inhibit the mutagenicity of an alkylating agent, MNNG. The mutagenicity of MNNG detected using TA1535 was decreased in the presence of ganebu-K (Fig. 1e). The $\mathrm{ID}_{50}$ value for ganebu-K, $0.050 \mathrm{~mL}$ and $23.1 \mathrm{mg}$, was similar to that for yamabudo, at $0.1 \mathrm{~mL}$ and $18.8 \mathrm{mg}$. As MNNG is a direct-acting mutagen, mechanisms for antimutagenicity have no relation to its metabolic activation. MNNG begins its actions by forming methyl-adducts in DNA. If these are not removed, the adducts mispair with the wrong base during DNA replication, resulting in mutation. We examined whether the repair systems for methyl-adducts in DNA were targets of the antimutagenic components in ganebu-K. YG7108 is a derivative of the Ames tester strain TA1535, but has chromosomal deletions of both the ogt ${ }^{\mathrm{ST}}$ and $\mathrm{ada}^{\mathrm{ST}}$ genes encoding $O^{6}$-methylguanine DNA methyltransferases [13]. MNNG mutagenicity detected with S. typhimurium YG7108 was not decreased or increased in the presence of ganebu-K up to $100 \mu \mathrm{L} /$ plate (Fig. 1f). Thus, $O^{6}$-methylguanine DNA methyltransferases might be a target of the antimutagenic components in ganebu-K, which might accelerate the repair process, specifically enhancing the repair of DNA damage caused by MNNG and reducing cellular DNA damage [10].

We investigated the anti-inflammatory activity of ganebu-K. Topical application of ganebu-K to mouse dorsal sides resulted in potent suppression of acute edema induced by TPA (Fig. 2a), as did yamabudo and DBQ. To further investigate the mechanism of the antiinflammatory activity of ganebu-K, the effect on PGE2 induction in mouse skin treated with TPA was investigated. In experiments involving topical application, as shown in Fig. 2b, ganebu-K significantly inhibited the induction of PGE2 induced by TPA. No significant inhibition of PGE2 induction was observed with yamabudo. Some particular components in ganebu- $\mathrm{K}$ that are not present in yamabudo might inhibit the induction of PGE2. These results also suggest that components in ganebu-K can be transcutaneously imported to target cells and eventually lead to the suppression of the inflammatory response via suppression of PGE2 induction. 
Fruits and vegetables that contain antioxidants have been hypothesized to decrease the risk of various diseases, including cancer. The relationship between the antioxidant and anticancer activities of plant polyphenols, flavonoids, and anthocyanins in berries and grapes is well known [21, 22]. A plant polyphenol, resveratrol, has been proven to have antioxidant, anti-inflammatory, and anticancer effects [23], and the antioxidant properties of components in yamabudo seeds have been reported [24]. We investigated the antioxidant activities of ganebu-K juice using an in vitro lipid peroxidation assay. We found that ganebu-K significantly decreased lipid peroxidation (Fig. 3). In our previous study, in vitro lipid peroxidation was inhibited in the presence of $5-10 \%$ eq. of the original yamabudo juice [10], but a smaller amount of ganebu-K $(0.5 \%)$ showed effective antioxidative activity. In our previous research [10], TBARS level in the supernatant of $\mathrm{t}$-BHP-treated liver decreased dose-dependently to the level of the negative control in the presence of yamabudo (10\%). However, in the presence of ganebu-K (from 0.5 to $10 \%$ ), TBARS levels in the supernatants of t-BHP-treated livers significantly decreased by $50 \%$ but not to the level of negative control and no dose response was observed. There might be another components in ganebu-K conflict with antioxidative components. Petroski and Minich [25] discussed whether plant-food consumption are beneficial because of the various 'anti-nutrient' compounds they contain. Lectins were suggested to cause inflammation [25]. Similar 'anti-nutrient' components in Ganebu- $\mathrm{K}$ might be implicated in TBARS level. Both ganebu-K and yamabudo inhibited in vivo lipid peroxidation and decreased the GOT level induced by $\mathrm{CCL}_{4}$ treatment (Fig. 4). A non-polyphenolic component in yamabudo, DBQ, inhibited in vivo lipid peroxidation and decreased the GOT level induced by $\mathrm{CCL}_{4}$ treatment. Lipid peroxidation is an indicator of oxidative stress caused by reactive oxygen species (ROS), which play a critical role in cell death and oxidative cell damage [26]. Previously, we found that oral intake of yamabudo or DBQ affords significant protection against lung and skin carcinogenesis in mice, and antioxidant and anti-inflammatory activities were observed as possible antitumorigenic mechanisms [10]. As shown in Figs. 2, 3 and 4, ganebu-K also had in vivo antioxidant and anti-inflammatory activities.

In conclusion, the present study demonstrated that ganebu-K inhibited the mutagenic activity of several carcinogens that are model compounds of tumor initiation. Ganebu-K also inhibited the induction of acute inflammation in a mouse model and reduced lipid peroxidation in vitro and in vivo. Ganebu-K may have unique components that are not in yamabudo that are responsible for the inhibition of PGE2 induction. Components in ganebu- $\mathrm{K}$ juice are not the same as those in yamabudo.
Unfortunately, antimutagenic and anti-inflammatory substances in ganebu- $\mathrm{K}$ are not identified. Investigation of the types and structures of antimutagenic and antiinflammatory constituents in ganebu- $\mathrm{K}$ and compare the amounts of them is worth for further investigations. Our results suggest that components in ganebu-K juice are attractive candidates for chemopreventive agents.

\section{Abbreviations}

MelQx: 2-Amino-3,8-dimethyl-3H-imidazo[4,5-f]quinoxaline; IQ: 2-Amino-3methylimidazo(4,5-f)quinoline; Trp-P-2: 3-Amino-1-methyl-5H-pyrido[4,3b]indole; t-BHP: tert-Butyl hydroperoxide; DBQ: 2,6-Dimethoxy-1,4benzoquinone; DPPH: 1,1-Diphenyl-2-picrylhydrazyl; DMBA: 7,12-

Dimethylbenzoanthracene; GOT: Glutamic oxaloacetic transaminase; Trp-P2(NHOH: 3-Hydroxyamino-1-methyl-5H-pyrido[4,3-b]indole; MNNG: 1-Methyl3-nitro-1-nitrosoguanidine; PGE2: Prostaglandin E2; S9: Supernatant fraction of rat liver homogenate; TPA: 12-O-tetradecanoylphorbol-13-acetate;

TBARS: Thiobarbituric acid reactive substance

\section{Acknowledgements}

Not applicable.

\section{Authors' contributions}

Sakae Arimoto-Kobayashi designed and conducted the experiments. Ryoko Hida conducted experiments on anti-inflammatory activities and in vitro lipid peroxidation. Nana Fujii performed the in vivo lipid peroxidation assays. Ryosuke Mochioka provided ganebu samples and identified the sample species as Vitis ficifolia var. ganebu. All authors approved the final manuscript.

Funding

Not applicable.

Availability of data and materials

Not applicable.

\section{Declarations}

Ethics approval and consent to participate

Not applicable.

Consent for publication

Not applicable.

\section{Competing interests}

The authors declare that they have no competing interests.

\section{Author details}

${ }^{1}$ Graduate School of Medicine, Dentistry and Pharmaceutical Sciences, Okayama University, 700-8530 Okayama, Japan. ${ }^{2}$ Faculty of Pharmaceutical Sciences, Okayama University, 700-8530 Okayama, Japan. ${ }^{3}$ Faculty of Agriculture, University Farm, Kagawa University, 769-2304 Kagawa, Japan.

Received: 9 August 2021 Accepted: 21 October 2021

Published online: 12 November 2021

\section{References}

1. World Cancer Research Fund and American Institute for Cancer Research. Food, nutrition, physical activity, and the prevention of cancer: a global perspective. London: World Cancer Research International; 2007.

2. Gautam S, Saxena S, Kumar S. Fruits and vegetables as dietary sources of antimutagens. J Food Chem Nanotechnol. 2016. https://doi.org/10.17756/ jfcn.2016-018.

3. Rodriguez-Casado A. The health potential of fruits and vegetables phytochemicals: notable examples. Crit Rev Food Sci Nutr. 2016. https://doi. org/10.1080/10408398.2012.755149.

4. Ding $M$, Feng $R$, Wang SY, Bowman $L$, Lu Y, Qian Y, Castranova $V$, Jiang BH, Shi X. Cyanidin-3-glucoside, a natural product derived from Blackberry, exhibits chemopreventive and chemotherapeutic activity. J Biol Chem. 2006. https://doi.org/10.1074/jbc.M600861200. 
5. Ye X, Krohn RL, Liu W, Joshi SS, Kuszynski CA, McGinn TR, Bagchi M, Preuss HG, Stohs SJ, Bagchi D. The cytotoxic effects of a novel IH636 grape seed proanthocyanidin extract on cultured human cancer cells. Mol Cell Biochem. 1999:196:99-108.

6. Amararathna M, Johnston MR, Vasantha Rupasinghe HP. Plant polyphenols as chemopreventive agents for lung cancer. Int J Mol Sci. 2016. https://doi. org/10.3390/ijms17081352.

7. Zhang X, Ishida R, Yuhara Y, Kamiya T, Hatano T, Okamoto G, ArimotoKobayashi S. Anti-genotoxic activity of Vitis coignetiae Pulliat towards heterocyclic amines and isolation and identification of caftaric acid as an antimutagenic component from the juice. Mutat Res. 2011. https://doi.org/1 0.1016/j.mrgentox.2011.05.001.

8. Kamiya T, Tanimoto Y, Fujii N, Negishi T, Suzuki T, Hatano T, ArimotoKobayashi S. 2,6-dimethoxy-1,4-benzoquinone, isolation and identification of anti-carcinogenic, anti-mutagenic and anti-inflammatory component from the juice of Vitis coignetiae. Food Chem Toxicol. 2018. https://doi.org/10.101 6/j.fct.2018.10.028.

9. Arimoto-Kobayashi S, Zhang X, Yuhara Y, Kamiya T, Negishi T. Chemopreventive effects of the juice of Vitis coignetiae Pulliat on two-stage mouse skin carcinogenesis. Nutr Cancer. 2013. https://doi.org/10.1080/0163 5581.2013 .767916

10. Arimoto-Kobayashi S, Sasaki K, Hida R, Miyake N, Fujii N, Saiki Y, Daimaru K, Nakashima H, Kubo T, Katsuyuki Kiura K. Chemopreventive effects and antitumorigenic mechanisms of 2,6-dimethoxy-1,4-benzoquinone, a constituent of Vitis coignetiae Pulliat (crimson glory vine, known as yamabudo in Japan), toward 4-(methylnitrosamino)-1-(3-pyridyl)-1-butanone (NNK)-induced lung tumorigenesis in A/J mice. Food Chem Toxicol. 2021. https://doi.org/10.101 6/j.fct.2021.112319.

11. Nakagawa S, Horiuchi S, Matsui H, Yuda E, Yamada S, Murai Y, Komatsu H. Distribution and leaf morphology of wild grapes native to Japan. J Japan Soc Hort Sci. 1991;60:31-9. https://doi.org/10.2503/jjshs.60.31.

12. Maron DM, Ames BN. Revised methods for the Salmonella mutagenicity test. Mutat Res. 1983;113:173-215.

13. Yamada M, Matsui K, Sofuni T, Nohmi T. New tester strains of Salmonella typhimurium lacking $\mathrm{O}^{6}$-methylguanine DNA methyltransferases and highly sensitive to mutagenic alkylating agents. Mutat Res. 1997. https://doi.org/1 0.1016/s0027-5107(97)00139-5.

14. Saito K, Yamazoe $Y$, Kamataki T, Kato R. Synthesis of hydroxyamino, nitroso and nitro derivatives of Trp-P-2 and Glu-P-1, amino acid pyrolysate mutagens, and their direct mutagenicities towards Salmonella typhimurium TA98 and TA98NR. Carcinogenesis. 1983;4:1547-50.

15. Arimoto-Kobayashi S, Sugiyama C, Harada N, Takeuchi M, Takemura M, Hayatsu $\mathrm{H}$. Inhibitory effects of beer and other alcoholic beverages on mutagenesis and DNA adduct formation induced by several carcinogens. J Agric Food Chem. 1999. https://doi.org/10.1021/jf980685a.

16. Yamazoe $Y$, Nagata K. In vitro metabolism. In: Nagao M, Sugimura T, editors. Food borne carcinogens. Chichester: Wiley; 2000. p. 74-89.

17. Harvey RG. Polycyclic aromatic hydrocarbons: chemistry and carcinogenicity. Cambridge: Cambridge University Press; 1991.

18. Shimada T, Murayama N, Yamazaki H, Tanaka K, Takenaka S, Komori M, Kim D, Guengerich FP. Metabolic activation of polycyclic aromatic hydrocarbons and aryl and heterocyclic amines by human cytochromes P450 2A13 and 2A6. Chem Res Toxicol. 2013. https://doi.org/10.1021/tx3 004906.

19. Marczylo T, Arimoto-Kobayashi S, Hayatsu H. Protection against Trp-P-2 mutagenicity by purpurin: mechanism of in vitro antimutagenesis. Mutagenesis. 2000. https://doi.org/10.1093/mutage/15.3.223.

20. Hiramoto K, Negishi K, Namba T, Katsu T, Hayatsu H. Superoxide dismutasemediated reversible conversion of 3-hydroxyamino-1-methyl-5H-pyrido[4,3b]indole, the N-hydroxy derivative of Trp-P-2, into its nitroso derivative. Carcinogenesis. 1988. https://doi.org/10.1093/carcin/9.11.2003.

21. Baby B, Antony P, Vijayan R. Antioxidant and anticancer properties of berries. Crit Rev Food Sci Nutr. 2018. https://doi.org/10.1080/10408398.201 7.1329198

22. Luo H, Yang A, Schulte BA, Wargovich MJ, Wang GY. Resveratrol induces premature senescence in lung cancer cells via ROS-mediated DNA damage. PLoS One. 2013. https://doi.org/10.1371/journal.pone.0060065.

23. Kisková T, Kassayová M. Resveratrol action on lipid metabolism in cancer. Int J Mol Sci. 2019. https://doi.org/10.3390/ijms20112704.

24. Weidner S, Rybarczyk A, Karamać M, Król A, Mostek A, Grębosz J, Amarowicz $\mathrm{R}$. Differences in the phenolic composition and antioxidant properties between Vitis coignetiae and Vitis vinifera seeds extracts. Molecules. 2013. https://doi.org/10.3390/molecules18033410.

25. Petroski W, Minich DM. Is there such a thing as "anti-nutrients"? A narrative review of perceived problematic plant compounds. Nutrients. 2020. https:// doi.org/10.3390/nu12102929.

26. Su L-J, Zhang J-H, Gomez H, Murugan R, Hong X, Xu D, Jiang F, Peng Z-Y. Reactive oxygen species-induced lipid peroxidation in apoptosis, autophagy, and ferroptosis. Oxid Med Cell Longev. 2019. https://doi.org/1 $0.1155 / 2019 / 5080843$

\section{Publisher's Note}

Springer Nature remains neutral with regard to jurisdictional claims in published maps and institutional affiliations.
Ready to submit your research? Choose BMC and benefit from:

- fast, convenient online submission

- thorough peer review by experienced researchers in your field

- rapid publication on acceptance

- support for research data, including large and complex data types

- gold Open Access which fosters wider collaboration and increased citations

- maximum visibility for your research: over $100 \mathrm{M}$ website views per year

At BMC, research is always in progress.

Learn more biomedcentral.com/submissions 